I- 718

h.

168

MASTER

\title{
BREAKEVEN COSTS OF STORAGE IN OPTIMIZED SOLAR ENERGY SYSTEMS
}

R.W. Leigh

BNL- -51428

September 1981

DE82 006967

Prepared for the

TECHNICAL AND ECONOMIC ANALYSIS BRANCH

DIVISION OF ENERGY SYSTEMS RESEARCH

NATIONAL CENTER FOR ANALYSIS OF ENERGY SYSTEMS

DEPARTMENT OF ENERGY AND ENVIRONMENT

BROOKHAVEN NATIONAL LABORATORY

UPTON, NEW YORK 11973

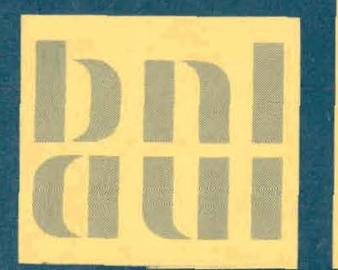




\section{DISCLAIMER}

This report was prepared as an account of work sponsored by an agency of the United States Government. Neither the United States Government nor any agency Thereof, nor any of their employees, makes any warranty, express or implied, or assumes any legal liability or responsibility for the accuracy, completeness, or usefulness of any information, apparatus, product, or process disclosed, or represents that its use would not infringe privately owned rights. Reference herein to any specific commercial product, process, or service by trade name, trademark, manufacturer, or otherwise does not necessarily constitute or imply its endorsement, recommendation, or favoring by the United States Government or any agency thereof. The views and opinions of authors expressed herein do not necessarily state or reflect those of the United States Government or any agency thereof. 


\section{DISCLAIMER}

Portions of this document may be illegible in electronic image products. Images are produced from the best available original document. 


\section{BREAKEVEN COSTS OF STORAGE IN OPTIMIZED SOLAR ENERGY SYSTEMS}

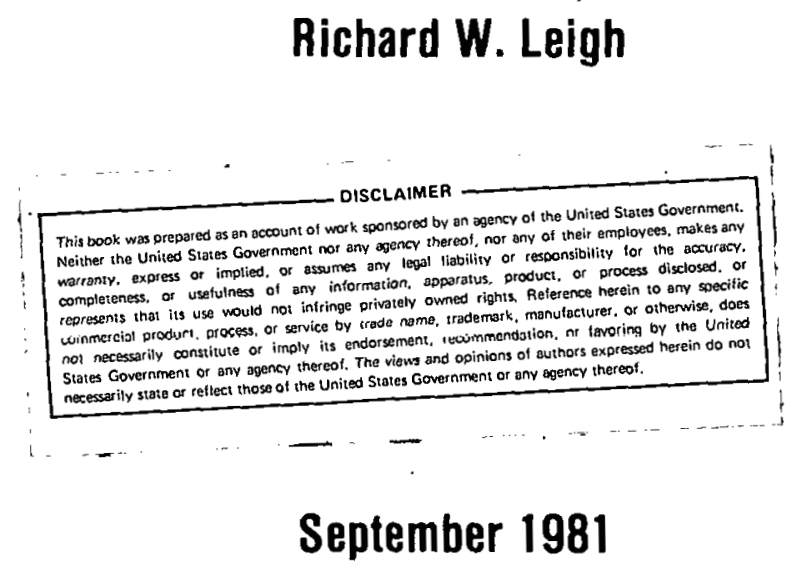

Prepared for the

TECHNICALL ANO ECONOMIC ANALYSIS BRANCH

DIVISION OF ENERGY SYSTEMS RESEARCH

UNITED STATES DEPARTMENT OF ENERGY

by the

TECHNOLOGY AND DATA DIVISION

NATIONAL CENTER FOR ANALYSIS OF ENERGY SYSTEMS

DEPARTMENT OF ENERGY AND ENVIRONMENT

BROOKHAVEN NATIONAL LABORATORY

ASSOCIATED UNIVERSITIES, INC.

UNDER CONTRACT NO. DE-ACO2-76CHDOO16 WITH THE UNITED STATES DEPARTMENT OF ENERGY 


\section{DISCLAIMER}

This report was prepared as an account of work sponsored by an agency of the United States Government. Neither the IInited States Rnvernment nor any agency thereof, nor any of their employees, nor any of their contractors, subcontractors, or their employees, makes any warranty, express or implied, or assumes any legal liability or responsibility for the accuracy, completeness, or usefulness of any information, apparatus, product, or process disclosed, or represents that its use would not infringe privately owned rights. Reference herein to any specific commercial produci, process, or service by trade name, trademark, manulactures, us otherwise, does not necessarily constitute or imply its endorsement, recommendation, or favoring by the United States Government or any agency, contractor or

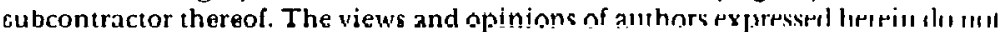
necessarily state or reflect those of the United States Government or any agenry, contractor or subcontracior thereof.

Printed in the United States of America Available from

National Trrhniral Information Servire

U.S. Department of Commerce

5285 Port Royal Road

Springfield, VA 22161

NTIS price codes:

Printed Copy: A03; Microfiche Copy: A01 
This paper describes the results of an analysis of the breakeven cost, or value, of energy storage to solar energy systems. I show that the value of storage depends strongly both on solar fraction of the solar energy system in which the storage is employed, and on the cost of the collectors used in the system. Various strategies for dealing with this ambiguity are presented, and I show that for a broad class of technically and economically practical solar energy systems, storage costs need on $1 y$ be low enough to make a system employIng very small amounts of storage practical. Reductions in cost of collectors will thereafter produce greater reductions in the total system costs or provide greater fuel displacement at constant total system cost than will reductions in the cost of storage, within limits discussed in the body of the paper. The analysis makes use of a simple, accurate representation of solar energy system performance which may prove useful in other contexts.

\section{ACKNOWLEDGEMENTS}

I would like to thank $\mathrm{Dr}$. V. Rabl for raising some of the questions considered herein, Dr. Ted Teichmann for suggesting the hyperbolic tangent form, and S. White-DePace and H. Sorrells for their quick and accurate typing of this manuscript. 
THIS PAGE

\section{WAS INTENTIONALLY LEFT BLANK}




\section{CONTENTS}

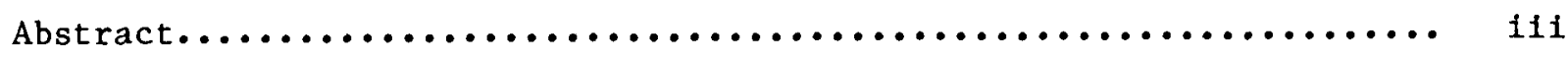

1. Introduction................................... 1

2. Summary of Results............................. 5

3. Describing the Technical Performance of Solar Energy Systems...... 7

4. Optimized Solar Finergy Systems...................... 13

5. The Value of Storage - Dependence on Solar Fraction........... 19

6. The Value of Storage - Dependence on Cost of Collectors........ 25 


\section{INTRODUCTION}

This paper is an attempt to clarify some ambiguities in the definition of "breakeven costs" or the "value" of energy storage in optimized solar energy systems. These ambigulties have arisen in the course of analysis of the possible uses of energy storage devices which are now under development funded by the Department of Energy (DOE). Discussion of the ambiguities requires a clear understanding of the concepts involved, so I begin with some definitions.

I will be discussing solar energy systems which are designed to meet wel1defined loads under specified weather conditions. Although a wide range of components can actually be used in such systems, a configuration consisting of collector area, storage capacity, and a backup system will prove sufficiently detailed for this discussion. The annual fuel consumption, for specified weather conditions and load, w111 depend on the collector area and storage capacity. We will assume that the fuel consumption has been determined for a set of points in this collector area - storage capacity (c-s) space either from detailed simulation or from experiment. The discussion applies to a wide range of solar energy systems, including those delfvering hot water, space heat, process heat, or electricity. The range of possible storage devices is correspondingly broad.

Both the amount of fuel and the total cost of the system will vary as the collector area and storage capacity are changed, and in general there 1 s a specific pair of areas and capacities for which the system cost is a minimum, given the load, weather, and other exogenous variables. This is an "optimized system." A well-known result, discussed in a succeeding section, is that in an optimized system, the cost of an additional unit of collector or storage is just equal to the value of the fuel it will save when all outlays are levelized over the life of the system.

A quantity of interest to research and development ( $R$ and $D$ ) planners is the "breakeven cost" or "value" of storage (or of any other component of an energy system). The breakeven cost of a device is an application-specific estimate of what the device is worth. This quantity is of interest because in plainlng $R$ and $D$ almed at lowering the cost of currently expensive components, the existence of a quantitative cost target provides focus for the $R$ and $D$ program. The breakeven cost is just such a target, and since the goal is to speed the development of economically attractive energy systems, we define the breakeven cost to be simply the price a designer of optimized systems would be willing to pay for the component in question. The breakeven cost of a device or system is thus an estimate of the cost of duplicating the function of the device or system by some alternative means. It is application specific and must be defined in terms of a clearly stated function for the device or system, an alternative way to get the same job done and, for the breakeven cost of a component, a clearly defined seț of costs for the other components in the system. 
However, a problem has already arisen: If we are seeking a value, we do not know the cost of the component, so we do not know how to optimfze the system. A partial answer is that we can have systems optimized with respect to the other components, the collector area in particular, as long as we know the collector costs. It is important to remember, however, that the amount of collector in an optimized system will depend on the amount of storage in that system, whether we know what the storage costs, or are finding what it is worth. Changing the amount of storage will change the technical and economic characteristics of the optimized system and thus the environment in which the storage is to be evaluated. Inescapably then, changing the amount of storage will also change the value of storage.

However, for any given configuration, we can unambiguously define the marginal value of storage as being equal to the value of the fuel displacement and other savings attributable to a small incremental increase in the storage capacity, divided by that increase in capacity. (Other notions, such as an "average" value for storage will be discussed below.) Since a value for atorage is sought, the calculation must not include any costs for the storage or for the increase in storage capacity.

We have already discussed the first significant ambiguity. Since the value of storage depends on the amount of storage in the system, it is not well defined even in a single system. Changing the amount of storage by any substantial amount will, for an optimized system, change the amount of collector and the amount of fuel consumed, resulting in a change in the fuel that would be displaced by an incremental amount of storage and hence changing the value of storage. It is one of the purposes of this paper to examine the nature of the dependence of the value of storage on solar fraction (or, equivalently, on the amount of storage in the system) and to suggest some conventions to deal with this ambiguity.

Assuming that we have found some way to deal with this problem, several others arise immediately. We have discussed value in the context of a given system and a given application, but the concept was developed as an aid to Research and Development ( $R$ and $D$ ) planning, and so should be applicable to a device used in the same system in several different applications or in different systems. This ambigulty is much more easily dealt with: we find a set of breakeven costs, one for each posslble application of the device, and simply assert that the value of relevance to $R$ and $D$ planning is the highest one (and therefore the one that is easiest to attain) which will allow a substantial market for the device to develop. We may, for example, use as $R$ and $D$ breakeven costs those obtalned for a storage device in a solar energy system operating in the Southwest where the solar resource is greatest. Storage devices produced at that price might not be economically leasible in the Northcast, but the existence of a large market in the Southwest should ensure that subsequent costs will drop due to experience gained in production, if any further decline in costs is possible. 
One more substantial ambiguity remains. I have pointed out that the value of storage depends on the technical and economic characteristics of the system in which it is evaluated. Some of these characteristics are not known - future fuel prices for example - but. will be determined exogenously when the time comes. We can account for this uncertainty by determining value under a set of possible future costs and taking note of how economic viability depends on them. Often, for example, comparison of the breakeven cost of two storage devices which are both competing for $R$ and $D$ funds shows that, the relationship of the values of the devices being compared will not vary greatly as fuel costs change, even though their absolute values might alter significantly.

However, some future costs, most notably the costs of collectors, may be significantly altered by $K$ and $D$ funding decisions made now in response to analyses similar to the type I have been discussing for storage devices, but where the costs of storage are assumed known and breakeven costs for collectors are sought. This raises the question of how $R$ and $D$ funding directed at lowering component costs should be allocated between collectors, storage, and (possibly) other components. Although such decisions involve much more than pure technical analysis, it is good to know how much analysis can tell us about the issue, so that discussions can be based on clear understanding of the technical 1ssues.

Assuming that conventions have been found which deal with the ambiguities discussed above, the allocation of cost goals between storage and collectors does have an analytically complete answer which is useless in practice. That is to find that set of collector costs and storage cost for which the national total of $R$ and $D$ expenses, outlays to purchase the systems for the whole country, and total residual fuel expenses is minimized. The main reason this approach is unsatisfactory is the impossibility of predicting how much a given $R$ and $D$ expenditure will reduce the costs of solar or storage devices. The second lies in its dependence on a set of market assumptions or estimates of total national 1mplementation which are, in fact, extremely uncertain. A third problem is the assumption that once these systems are brought to the point of economic feasibility, they will simply be installed; in fact, it is most likely that initial implementation of some system or device on any reasonable scale w111 give rise to a flurry of spontaneous innovation which will result in some quite different (and better) system actually being installed. The unfortunate fact is that the uncertainties associated with this approach are great enough to render 1 t useless as a quantitative planning tool. The questions raised are important, but must be dealt with qualitatively and judgmentally.

Therefore, in this paper, I will examine only individual solar energy systems to determine the relative merits of lowered costs in collectors or in storage. It may be that some future investigator will find a way to bring some estimate of $R$ and $D$ costs and other data external to the individual systems to bear on the problem without succumbing to the dangers described in the preceding paragraph. 
Investigators have at various times discussed the indirect benefits of solar energy, such as decreased environmental degradation and the retention of economic benefits within local communities or (for the case of ofl displacement) within the nation. Such considerations are an important component of $R$ and $D$ planning, and the various benefits may be described as increasing the "value" of solar energy tehnologies. These considerations are not dealt with explicitly in this paper, but may be included in most cases by making appropriate adjustments to the costs of fuel or of solar energy components so that the numbers used reflect both direct and indirect costs and benefits.

One other subject which is developed in the following sectlons should be mentioned. I have developed, and here present, an analytic description of the annual operating characteristics of solar energy systems in terms of collector area and storage capacity. I'his consists of a fuul paldulel eyuation which describes fuel consumption as a function of collector area and storage capacity, and which can then be solved to yleld closed-form expressions for the sizes and characteristics of optimized systems and various other relations of interest. This description will prove useful $l_{\text {n }}$ malu areas of analysis, since a few (expensive) simulation runs will yield the values of the necessary parameters, and economic and technical analysis for a variety of possible economic futures may then be carried out by evaluating simple expressions.

Due to constraints of time, I have not dealt in detail with the behavior of systems which can sell some of their energy back to a larger entity, such as electricity to a utility. The fuel consumption behavior of such systems will be quite different from isolated systems, and if electricity is counted as fuel, they may actually be net producers. A more general formulation is necessary to describe the economic behavior of such systems.

Section 2 is a summary of the results. Section 3 describes the analytic treatment of the technical characteristics of solar energy systems. Section 4 brings in cconomic factors and develops the equations describling optimlzed systems. Sections 5 and 6 then use these terms to discuss the value of storage and to clarify the nature of the ambiguities $I$ have just described, dealing in particular with the dependence of value on solar fraction and with the tradeoffs between the costs of collectors and the costs of storage. 


\section{SUMMARY OF RESULTS}

Assuming that collector costs $\left(\lambda_{c}\right)$ and other economic and technical variables are known, the value of storage $\left(\lambda_{S}\right)$ is a monotonically decreasing function of storage capacity $(s)$ or solar fraction $(\sigma)$. The maximum value of $\lambda_{s}, \lambda_{s o}$, occurs at a well defined $\sigma=\sigma_{0}$, when the first unit of storage is added. The value of storage drops to zero at another well defined solar fraction, $\sigma_{m}$, although at this point the amount of storage is large and not well defined. The ambigulty over what value of storage to use $-\lambda_{\text {so }}$ or some lower value appropriate to some solar fraction between $\sigma_{0}$ and $\sigma_{\mathrm{m}}$ - seems unavoidable, and I recommend that some arbitrary definition be adapted for the sake of consistancy. Two possibilities are:

$$
\begin{aligned}
& B_{0}=\lambda_{s o} ; \sigma=\sigma_{o}, \\
& B_{1}=\lambda_{s o} / 2 ; \sigma=\sigma\left(\lambda_{s o} / 2\right) .
\end{aligned}
$$

others are listed in section 4. This ambiguity is not as serious as it might seem for reasons discussed in the next few paragraphs.

The question of the dependence of the value of storage on collector costs is somewhat more complex. Clearly it is unsatisfactory to have storage breakeven costs vary dramatically as collector costs are varied, but more to the point, both storage costs and collector costs are subject to decrease through $R$ and $D$ investment, and the real task is to determine how to allocate effort between collector cost reduction and storage cost reduction. To investigate the dimensions of this question, I developed isosolar and 1socost plots of the loci of optimized systems in the $\lambda_{s}-\lambda_{c}$ plane. For the 1sosolar plots (curves of constant solar fraction) the optimal pair of $\lambda_{c}$ and $\lambda_{s}$ was defined as that pair which gave the lowest total cost for a system of given solar fraction. This proved to be the case of $\lambda_{c}=0$ and $\lambda_{s}$ quite large. This indicates that 1t appears most efficlent to bring the cost of storage down to the regime where some optimlzed systems, probably of low solar fraction, are possible, and let the developers of collectors bear the burden of reducing collector costs, and hence total system costs, further.

This result was borne out by the results of examination of the isocost plots. Here, systems having the same total cost were plotted as curves in the $\lambda_{c}-\lambda_{s}$ plane, and solar fraction calculated along them. Maximum solar fraction (and hence maximum fuel displacement) is found to occur at falrly stringent storage costs, Implying that quite a bit of work is needed on cost reduction, but the plots indicated clearly that nelther total system costs or solar fraction depended dramatically on storage costs. In fact, variations in storage costs clearly have only minimal effects, while increases or decreases 
In collector costs have a direct and powerful impact on both total system costs and on solar fraction. Again the indication is that a reduction in collector costs is likely to produce lower cost, higher fuel displacement systems in the long run, once storage costs are brought down to levels where optimized systems are possible.

For this reason the ambiguity over what solar fraction should be used to determine the value of storage is not important; if the value Bo from Eq. (2-1) is attained, collector cost reduction would be the appropriate place to focus further energies, at least until a true point of diminishing return on $R$ and $D$ investment is reached.

This last point should be emphasized: I have determined relations between storage costs and collector costs which are in the specified senses optimal. This does not mean that $a l l ~ R$ and $D$ money should lmmediately flow one way or the other, since the return on the $R$ and $D$ dollar is quite uncertaln. These results should be used only as one of several inputs to funding decisions which must, in the end, be based on the informed judgment of the program managers and the institutions providing the funds. 
In this section I define and justify a four parameter equation which describes the annual technical performance of solar energy systems incorporating storage and a fuel-fired backup system in terms of total annual fuel consumption. The backup fuel could be oil or gas, but it could also be electricity from the grid, as long as the possibility of sell-back is excluded. (The equation, with the addition of a fifth parameter, can describe the sell-back situation if the capacity of the grid to absorb power is limited so that for attalnable collector areas some collected energy must be stored.)

The parameters are weather and load specilic, which is to say they must be obtained anew for systems operating in different climates or under different circumstances. They are not specific to particular amounts of storage capacity or collector area since they describe the dependence of fuel consumption on these variables. We will see in the next chapter that this is enough technical information to permit a complete economic description of all interesting configurations of the system. (A configuration is a specified pair of collector area and storage capactty; in more complex systems than are considered here, a configuration might involve the specification of the areas of several different types of collector, the capacitles of several different types of storage and so on.)

Let $F(c, s)$ represent annual fuel consumption as a function of collector area $\mathrm{c}$ and storage capacity s. Clearly as $\mathrm{c}$ and $\mathrm{s}$ increase, $\mathrm{F}(\mathrm{c}, \mathrm{s})$ will decrease. This behavior is demonstrated by the points plotted in Figure 3-1, which represent the fuel consumption of a solar total energy system operating in Albuquerque. 1

Economic analysis of solar energy systems can be performed by calculating or measuring fuel consumption at each of a set of discrete points (c,s) as shown here, but the process rapidly becomes tedious and expensive, especially if the simulation is detailed. Thus an analytic representation of this dependence of fuel consumption on $c$ and $s$ would be quite useful. I assert that an adequate analytic representation is:

$$
F(c, s)=F_{0}-\left(F_{O}-a(s)\right) \tanh \left(m c /\left(F_{o}-a(s)\right)\right)
$$

where

$$
a(s)=a_{0}\left(1-\tanh \left(m^{\prime} s / a_{0}\right)\right)
$$

and the four parameters $F_{O}, a_{O}, m$ and $m^{\prime}$ have the following interpretations: $F_{0}$ is the fuel consumed if $c=s=0$; $a_{0}$ is the fuel consumed if $s=0$ and $c$ is very large; $m$ is the fuel savings attributable to the first unit of collector, and $\mathrm{m}^{\prime}$ ' is the fuel savings attributable to the first unit of storago for very 


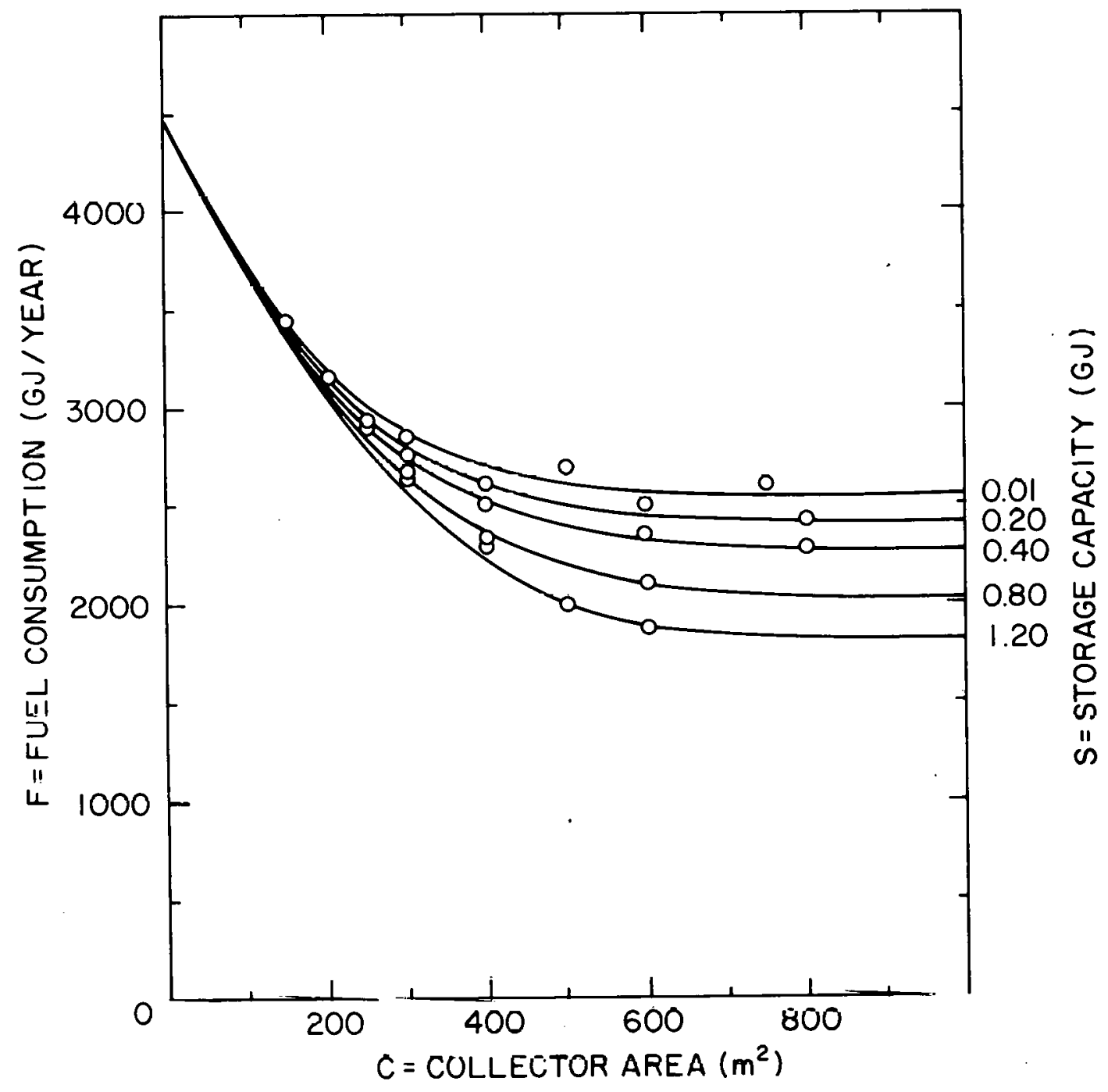

Figure 3-1

Fuel Consumption vs. Collector Area for Various Storage Capacities 
large collector areas. The curves are plotted in Figure 3-1 for storage capacities corresponding to the plotted data points, and the corresponding parameters $F_{O}, a_{O}, m$, and $m^{\prime}$ are shown in Table 3-1. The root mean square error is on the order of $3 \%$ at each of 28 points. (All figures in this report were generated using these parameters.) Fits to two other different systems have been equally accurate.

\begin{aligned} \hline & Table 3-1 \\ \hline $\mathrm{F}_{\mathrm{O}} & =4070.70 \mathrm{GJ} / \mathrm{yr} \\ \mathrm{a}_{\mathrm{O}} & =2652.57 \mathrm{GJ} / \mathrm{yr} \\ \mathrm{m} & =2.25901 \mathrm{GJ} / \mathrm{m}^{2}-\mathrm{yr} \\ \mathrm{m}^{\prime} & =650.369 \mathrm{GJ} / \mathrm{GJ}(\mathrm{cap})-\mathrm{yr} \\ \lambda_{\mathrm{F}} & =8.75 \$ / \mathrm{GJ} \\ \lambda_{\mathrm{c}} & =14.46 \mathrm{\$} / \mathrm{m}^{2}-\mathrm{yr} \\ &$ (when not a variable) \end{aligned}

The choice of this functional form was based on the nature of solar energy system operations. Consider the zero storage case. The f1rst few units of collector will be used to the greatest extent practical, since the arriving solar energy can always displace fuel. Thus fuel consumption declines linearly with collector area for small areas. This characteristic is independent of storage capacity, as long as collected energy need not be cycled through storage if $1 \mathrm{t}$ can be used directly. The expression for fuel consumption reflects this, since Eq. (3-I) reduces to $F(c, s)=F_{0}-m c$ for small values of $c$, independent of the size of $s$. This expression is not adequate for systems where all collected energy must be cycled through storage of less than $100 \%$ efficiency, even if the energy is to be used immediately. For these systems (solar ponds might be an example), the behavior at small $c$ may still depend explicitly on s. We will not consider such systems here.

Returning to consideration of the zero storage case, as more collector is added, it eventually can no longer be used effectively since some solar energy is arriving when it is not needed and is dumped. The fuel consumption curve bends up as a function of collector area and eventually becomes horizontal when the energy supplied by a new increment of collector area cannot be used at a11. Systems with storage operate similarly: for large collector areas, the first few units of storage are all used to the fullest and fuel consumption declines linearly as storage capacity is added. Eventually, however, capacity is added which is used only part of the time and the curve representing fuel consumption versus storage capaclty turns up. At very large storage capacities 
the fuel used at infinite collector area, $a(s)$, goes to zero and we have a system which is $100 \%$ solar. Under some circumstances, systems with the potential for net sales may be represented by adding a (negative) constant to Eq. (3-2) for $a(s)$.

For both the dependence of $a(s)$ on $s$ and the dependence of fuel consumption on $\mathrm{mc} /\left(\mathrm{F}_{\mathrm{O}}-\mathrm{a}(\mathrm{s})\right)$, the hyperbolic tangent forms used in Eqs. (3-1) and (3-2) were the simplest analytic forms which would have the appropriate behavior: a linear decrease in fuel consumption at small arguments, and an asymptotic approach to a limiting value for large arguments, with simple monotonic behavior between the limits. If greater accuracy is desired, and sufficient data are avallable to permit fitting more constants, a more flexible functional form could easily be created by adding to Eqs. (3-1) and (3-2) a series expansion in complete orthogonal functions having zeros for zero and infinite arguments.

If the solar fracliou $u$ is deflued as lial flaclium uf masimuin fuel consumption displaced by solar energy,

$$
\sigma(c, s)=1-F(c, s) / F_{0},
$$

then it is easy to show that

$$
\sigma(c, s)=\left(I-a(s) / F_{0}\right) \tanh \left(m c /\left(F_{0}-a(s)\right)\right)
$$

It is also straightforward to solve the equations for $c$, so if we know $s$, the storage capacity, and the desired solar fraction, $\sigma$,

$$
c=\left(\left(F_{0}-a(s)\right) / 2 m\right) \ln \left(\left(1-a(s) / b_{0}+\sigma\right) /\left(1-a(s) / F_{0}-\sigma\right)\right)
$$

Eq. (3-5) may be used to calculate isosolar curves (curves of constant solar fraction) such as are shown in Figure 3-2. Examination of the equations above shows that for a given solar traction $\sigma$, the requirement $c>0$ means that the argument of the logarithm in Eq. (3-5) must be greater than one. This in turn implies that

$$
a(s)<F_{0}(1-v)
$$

or

$$
s>\left(a_{0} / 2 m^{\prime}\right) \ln \left(2 a_{0} /(1-\sigma) F_{0}-1\right) \text {. }
$$


Simflarly, as $s$ gets very large a(s) approaches zero and Eq. (3-5) indicates that

$$
c>\left(F_{0} / 2 m\right) \ln ((1+\sigma) /(1-\sigma)) \text {, }
$$

where equality would hold in Eq. $(3-8)$ if $a(s)=0$.

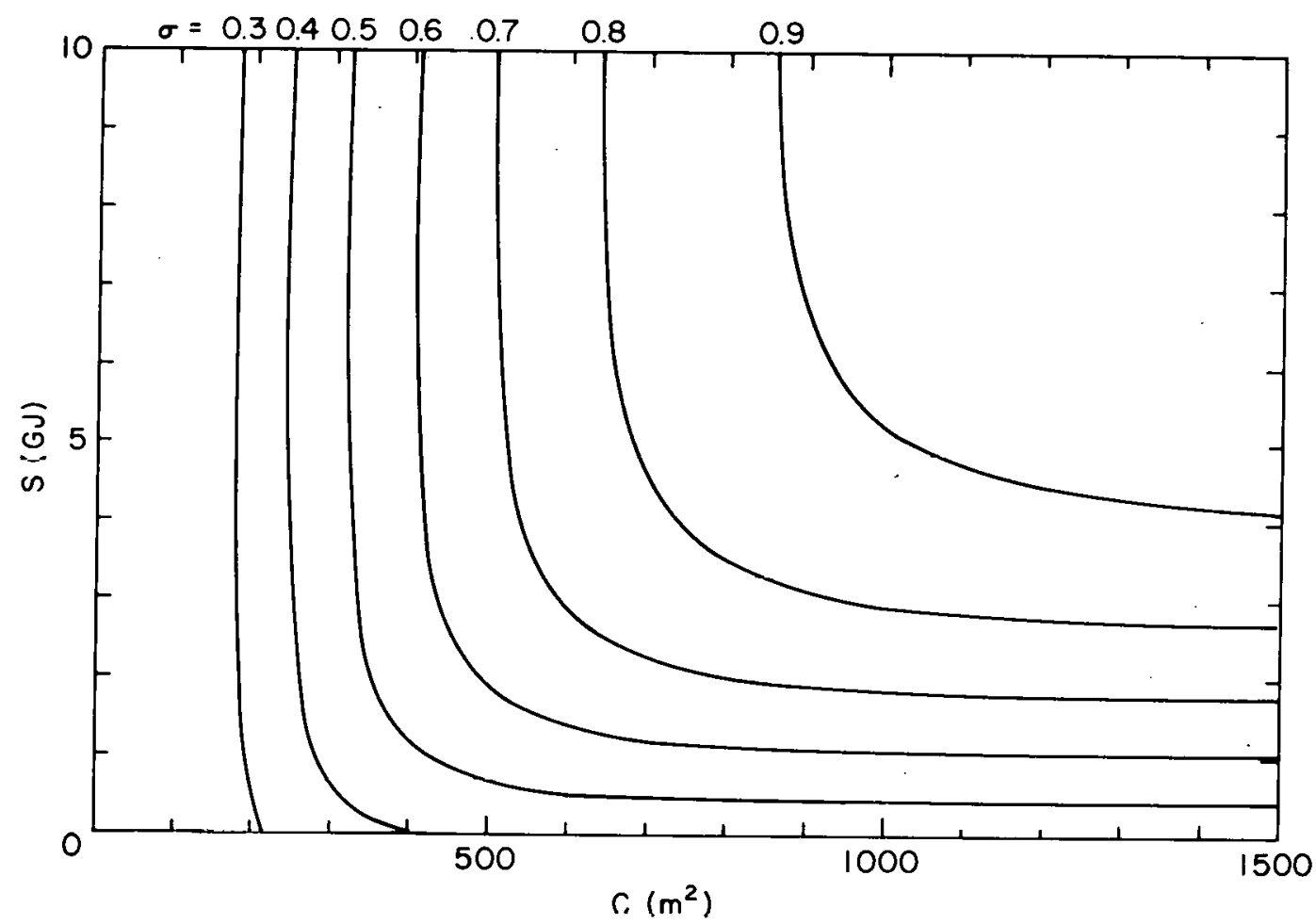

Figure 3-2

Storage Capacity vs. Collector Area for Constant Solar Fraction $\sigma$ 
These expressions are the asymptotic values of the "isosolars" plotted in Figure 3-2. Within the limits prescribed by Eqs. (3-6), to (3-8) any solar fraction may be obtained by any of the $(c, s)$ pairs on the appropriate curve. The detalled shapes of the curves, and in particular the numerical values obtained from them depend strongly on the parameters, obtained in turn from the simulations or experiments to which the expression for $F(c, s)$ was fitted. The general form of the curves, however, is remarkably similar for all the systems examined to date.

Note that Eqs. $(3-1),(3-3),(3-4),(3-5),(3-6)$, and $(3-8)$ do not depend on the exact form of $a(s)$. Examination of some systems indicated that the simpler form,

$$
\begin{aligned}
a^{\prime}(s) & =a_{0}\left(1-\mathrm{m}^{\prime} \theta\right), & & 0<1 / \mathrm{m}^{\prime}, \\
& =0, & & s \geq 1 / \mathrm{m}^{\prime},
\end{aligned}
$$

would give an adequate representation of the data. In this case, Eq. (3-7) would be replaced by

$$
\begin{array}{ll}
s>\left(1-(1-\sigma) \mathrm{F}_{0} / \mathrm{a}_{0}\right) / \mathrm{m}^{\prime}, & s<1 / \mathrm{m}^{\prime}, \\
0<(1-\sigma) \mathrm{F}_{0} / \mathrm{a}_{0}, & s>1 / \mathrm{m}^{\prime},
\end{array}
$$

the latter being no restriction. However, this form of a(s) gives perverse economic behavior due to the discontinuity in its slope, and so will not be exploited further in this report.

I have described the heuristic meaning of the four technical parameters $F_{O}, a_{O}$, m and $\mathrm{m}^{\prime}$ above, and in many cases this understanding will be enough to permit estimation of their values. If more precise data are avallable, such as the points plotted in Figure 3-1, standard least squares techniques can be used to find the values of the four parameters which allow Eqs. (3-1) and (3-2) to fit the data best. The parameter values listed in Table 3-1 and used to generate many figures in this report were determined from data from Reference 1 (the points shown) using a Newtonian search subroutine (ZXMIN) on the CDC 7600 at Brookhaven National Laboratory. 


\section{OPTIMIZED SOLAR ENERGY SYSTEMS}

The existance of the analytic expression for fuel consumption described in the preceding section makes possible closed form analytic expressions for many quantities derived from economic analyses of solar energy systems.. This is particularly useful since it means that expensive simulation programs, or even more expensive experiments, may be used sparingly to determine the four parameters above, and that the performance characteristics of systems optimized under a wide varlety of economic assumptions may then be derived from the technical representation. In this section I present various expressions which may be used for such an economic evaluation. In this section, I will assume all costs, including those of the storage devices, are known, and that we seek minimum cost (optimized) systems; breakeven costs will be introduced in the next section. All costs, including ongoing fuel and operations and maintenance charges ( $O$ and $M$ ) as well as lump sum capital outlays, are assumed to have been levelized in constant dollars over an assumed economic life of the system. All the equations are equally useful if one assumes that the quantities are all net present values of the outlays, over a similar economic life. I include no prescriptions for levelizing or finding net present values, since this subject has been treated in detail elsewhere. 2-5

The total annual system cost (or NPV, if you will) is given by:

$$
T=c \lambda_{c}+s \lambda_{s}+\lambda_{b}+\lambda_{F} F(c, s)+b_{c}+b_{s} \text {, }
$$

where:

$$
\begin{aligned}
& \lambda_{c}=\text { incremental cost of collectors per unit area, including } \\
& 0 \text { and } M \text {, replacement costs, and/or salvage value; } \\
& b_{c}=\text { buy in costs for collectors; } \\
& \lambda_{s}=\text { incremental cost of storage per unit of capacity, includ- } \\
& \text { ing } O \text { and } M \text {, replacement costs and/or salvage value; } \\
& b_{s}=\text { buy in costs for storage; } \\
& \lambda_{b}=\text { cost of balance of system, Including backup, power }
\end{aligned}
$$


The buy-in costs for collectors and storage are those costs incurred only when the first unft of collector or storage is installed. This would include piping or wiring, scaffolding or other rigging which could be used at no cost once installed, and control systems and power conditioning equipment. These costs are associated with equipment which would not be needed if no collection or storage were present and which does not have any costs depending on the actual area of collectors or capacity of storage. Wires or pipes leading up to the collectors might have to be increased in capacity as more collectors are added, and similar costs can be imagined for storage devices. I assume that these incremental costs are included in $\lambda_{c}$ and $\lambda_{s}$, while the initial costs of putting in wires or pipes of capacity sufficient to handle the smallest unit of collector are counted in the buy in costs. As has been pointed out, 6 the incremental cost of the first unit of storage is actually $b_{s}+\lambda_{s}$, while the cost of the second unit of storage is simply $\lambda_{s}$. This is admittedly simplification of actual decision-making processes, where a choice is probably based on smearing the buy-in costs over the whole project, but it will turn out to be a useful simplification in the discussions to follow. We will return to treat the effects of buy in costs in more detall at the end of this section.

In reality, cost functions more complex than the linear expressions used here will give a more accurate representation of the dependence of component costs on component size. For example, the costs of insulated tanks for storing hot water will more nearly scale with the surface area than with the volume, leading to an $s^{2 / 3}$ dependence on storage capacity. The use of more complex functions makes most of the closed form solutions to be derived below impossible, although the general approach remains valid. I will not pursue this avenue here, since the linear formulation may be used to represent the more general case in the following way: In investigations of realistic systems, one generally has or soon acquires a reasonable notion of the component sizes an optimized system will have. Then, if more complex cost/capacity curves are avallable, the two parameters $b_{s}$ and $\lambda_{s}$ (or $b_{c}$ and $\lambda_{c}$ ) may be adjusted to make the expression $b_{s}+\lambda_{s} s$ approximate both the value and slope of the more complex cost curve in the regime of interest. $b_{s}$ will no longer represent the "real" buy in cost, but results based on the linear approximation will closely mirror those which would be obtained from more complex component cost expressions.

$\Lambda \mathrm{n}$ optimal system is one for which the total costs are a minimum, a condition which obtains when:

$$
\left.\frac{\delta \mathrm{T}}{\delta \mathrm{c}}\right|_{\mathrm{c}^{\circ}, \mathrm{s}^{\circ}}=\left.\frac{\delta \mathrm{T}}{\delta \mathrm{s}}\right|_{\mathrm{c}^{0}, \mathrm{~s}^{\circ}}=0
$$

Here $c^{0}$ and $s^{0}$ are the values of $c$ and $s$ for which the minimum occurs. Substituting (4-1) into Eqs. (4-3), we find: 


$$
\left.\frac{\delta F}{\delta c}\right|_{c^{0}, s^{\circ}=-\lambda_{c} / \lambda_{F},}
$$

and

$$
\left.\frac{\delta F}{\delta s}\right|_{c^{0}, s^{0}}=-\lambda_{S} / \lambda_{F} \cdot
$$

Note that multiplying both sides by $\lambda_{F}$ shows that the costs of increments of collectors or of storage are just equal to the fuel that they save in these optimized systems.

We now seek explicit expressions for $c^{0}, s^{0}$, and $\sigma\left(c^{0}, s^{0}\right)$ or $F\left(c^{0}, s^{0}\right)$. Some definitions make the algebra simpler:

$$
\begin{aligned}
\alpha=\lambda_{\mathrm{c}} / \mathrm{m} \lambda_{\dot{\mathrm{F}}}, & 0<\alpha<1, \\
\beta=\ln (\sqrt{1 / \alpha}+\sqrt{1 / \alpha-1}), & \beta>0, \\
\delta=\sqrt{1-\alpha}-\alpha \beta, & 1>\delta>0, \\
\mu=\lambda_{\mathrm{S}} / \mathrm{m} \cdot \lambda_{\mathrm{F}} . & 0<\mu<1 .
\end{aligned}
$$

The range of values of each parameter is also shown; note that $\alpha$ gives incremental collector costs and $\mu$ incremental storage costs, measured in terms of the value of the fuel saved by the first unit of collector or of storage. Examination of Eq. (4-6) shows that if $\alpha$ were greater than one, even the first few units of collector would not be worth their cost in fuel and no optimized system would be possible. Note also that only $\mu$ involves $\lambda_{S}$, the cost of storage.

Equation (4-4) above may be solved for $c^{0}$ :

$$
c^{0}=\left(F_{0}-a(s)\right) B / m \text {. }
$$

This may be substituted into Eq. $(3-4)$ to yield

$$
\sigma=\left(1-a(s) / F_{0}\right) \sqrt{1-\alpha} \text {. }
$$


These, however, still depend on $s$ and so are not yet solutions. Substituting $(4-10)$ into $(4-5)$ does yield:

$$
\mathrm{s}^{0}=\left(\mathrm{a}_{\mathrm{o}} / \mathrm{m}^{\prime}\right) \ln (\sqrt{\delta / \mu}+\sqrt{\delta / \mu-1}),
$$

which is an expression for $s^{0}$ which depends only on the technical and economic parameters. $\quad c^{\circ}$ may be found by substituting this value for $s^{\circ}$ back into $(4-10)$ :

$$
c^{0}=\left(F_{0}-a_{0}(1-\sqrt{1-\mu / \delta})\right) B / m \text {. }
$$

Values for the fuel ronsumption, solar fraction, and coral cust of uplmi,zed systems may then be obtained by substituting the expressions for $c^{\circ}$ and su back into Eqs. $(3-1),(3-3)$, dild (4-1). The resulta arcs

$$
\begin{aligned}
& F\left(c^{0}, s^{0}\right)=F_{O}-\left(F_{0}-a_{0}(1-\sqrt{1-\mu / \delta})\right) \sqrt{1-\alpha} \\
& \sigma\left(c^{0}, s^{0}\right)=\left(1-\left(a_{0} / F_{0}\right)(1-\sqrt{1-\mu / \delta})\right) \sqrt{1-\alpha},
\end{aligned}
$$

and

$$
T\left(c^{0}, s^{0}\right)=c^{0} \lambda_{c}+s^{0} \lambda_{s}+\lambda_{b}+\lambda_{F} F\left(c^{0}, s^{0}\right)+b_{c}+b_{s}
$$

Note that while Eqs. (4-10) through (4-14) explicitly depend only un Llie four technical parameters and on $\lambda_{c}, \lambda_{s}$, and $\lambda_{F}, E_{4} .(4-15)$ muse have vur'iuver quantities from the preceeding equations substituted into it.

Examination of the definitions in Eqs. (4-6) through (4-9) and the results in Eqs. (4-12) through (4-16) reveals the following dependencies: In order to have a viable system with $c^{0}>0$, we must have $\alpha<1$ (the firet unlt of collector must save fuel equal to or greater in value than its cost). This gives $\beta>0$ and $\delta>0$. We must then have $\mu \leq \delta$ for these equations to apply, and if $\mu=\delta$ we have a system with non-zero collector area but zero storage. For $\mu>\delta$ the results obtained from Eqs. (4-12) through (4-16) for $\mu=\delta$ apply.

So far we have tacitly assumed that as collector prices fall or fuel prices rise there is a smooth transition from a non-solar system to one with arbitrarily small amounts of collectors or storagc. In practice this is not the case, due to the existance of the buy in costs $b_{c}$ and $b_{s}$, which will inhibit the purchase of solar equipment until the savings are sufficient to cover these initial outlays. ${ }^{7}$ In short, we must have 


$$
T\left(c^{0}, s^{0}\right)<T(0,0)
$$

which can be reduced to

$$
\begin{aligned}
b_{C}+b_{S}< & \lambda_{F} \delta\left(F_{O}-a_{O}(1-\sqrt{1-\mu / \delta})\right) \\
& -\lambda_{F} a_{O} \mu \ln (\sqrt{\delta / \mu}+\sqrt{\delta / \mu-1}) .
\end{aligned}
$$

If Eq. (4-18) is not satisfied, then the optimal system will have $c=s=0$, rather than collector area $c^{0}$ and storage $s^{\circ}$ from Eqs. (4-12) and (4-13). If $\mu \rightarrow \delta, E q .(4-18)$ will reduce to the prescription of constraints for the transition from a non-solar system to one with collector but no storage as $b_{S}$ is taken as zero.

The Eqs. (4-12) through (4-18) constitute a complete description of the relevant characteristics of optimized systems (fuel consumption and cost) in terms of $F_{O}, a_{O}, m$ and $m^{\prime}$ and the economic parameters defined in $\mathrm{Eq} \cdot(4-2)$. In this section, these have been the independent variables (Table 4-1) from which the characteristics of optimized systems were derived. We may now, for example, examine the dependence of total system cost or fuel consumption on the fuel prices, collector costs, or even discount rate just by varying. the appropriate parameters in (4-10) through (4-18). In the next section we use these algebraic results and examine the effects of assuming a different mix of dependent and independent variables.

Table 4-1

Independent Variables: $F_{O}, a_{0}, m, m^{\prime}, \lambda_{c}, b_{c}, \lambda_{s}, b_{s}, \lambda_{b}, \lambda_{F}$ Dependent Variables: $F, \sigma, c, s, T$ 


\section{THIS PAGE \\ WAS INTENTIONALLY \\ LEFT BLANK}




\section{THE VALUE OF STORAGE - DEPENDENCE ON SOLAR FRACTION}

In tlie InLluduction 1 developed the idea of breakeven cost and the motivation for using i.t. Here, I quantify these ideas, differentiate between the marginal and the average values of storage, and examine the dependence of the marginal value of storage on solar fraction or storage capacity. Finally, I will suggest some conventions for dealing with the ambiguities to be uncovered.

The marginal value of storage is defined as the value of the fuel saved by small increment of storage, divided by the capacity of that increment. (One might expect the marginal value of storage in an optimlzed system to include a credit or debit due to incremental changes in collector area following from the incremental change in storage capacity, but this is not the case: since the system was optimfzed before the increment of storage was added, an additional increment of collector will save fuel exactly equal to its cost, giving no net contribution to marginal storage value.) Equation (4-5) can be rewritten as:

$$
\lambda_{S}=-\left.\lambda F \frac{\delta F}{\delta s}\right|_{c^{0}, s^{\prime}}
$$

and this indicates a formal correspondence between $\lambda_{s}$, taken as the incremental cost of storage in the preceding section, and the incremental value, of storage. In fact, the only difference lies in which variables are taken as independent. In Section 4, we took $F_{O}, a_{0}, m, m^{\prime}, \lambda_{c}, \lambda_{s}, \lambda_{F}$, and the buy in and balance of system costs as independent. and found $c, s, \sigma$, and $T$ as dependent functions. Here we will leave $\lambda_{s}$ as a dependent variable to be determined from the characteristics of the rest of the system. But since we have no way of changing the number of equations, we must make some other variable independent. $\quad c=c^{0}$ will still be determined by the remaining technical and economic parameters, so we can only choose $s, \sigma, F$, or $T$. Whichever we choose, the other two and $\lambda_{S}$, will then be determined. These alternatives are displayed in Table 5-1; many other combinations are possible.

If $s$ is chosen as the independent variable, the results shown in Figure 5-1 are obtained. $c^{\circ}$ was obtained from Eq. (4-10), then $\sigma$ from $(4-11)$ and finally $\lambda_{s}$ was obtained by substituting $c^{\circ}$ into Eq. (5-1):

$$
\lambda_{S}=\lambda_{F^{m}} m^{\prime} \delta \operatorname{sech}^{2}\left(m^{\prime} s / a_{o}\right) .
$$

Hcre and subsequently, values of the parameters derlved from the fit described in Section 3 and from Reference 1, and displayed in Table 3-1, are used to generate the displayed curves. Note, in Figure 5-1, that the initial value of storage is $\lambda_{F^{m}} \delta>0$, and that $\lambda_{s}$ approaches zero asymptotically as $s$ gets large. 


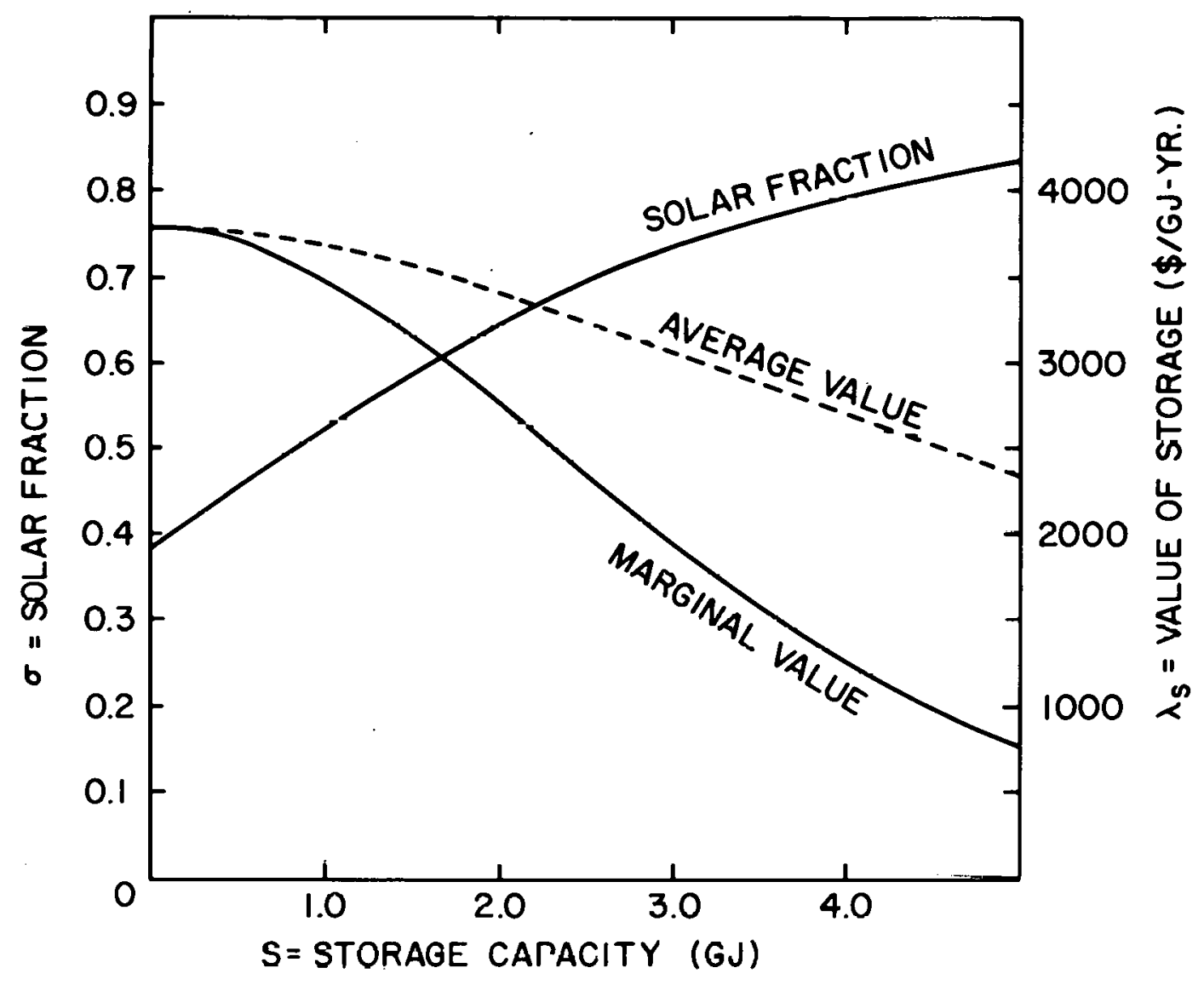

Figure 5-i

Solar f'raction aud Marginal and Average Valup of Storage vs. Storage Capacity 
Table 5-1

1) Let $s$ vary:

Independent Variables: $F_{o}, a_{o}, m, m^{\prime}, \lambda_{c}, b_{c}, \lambda_{b}, \lambda_{F}, s$ Dependent Varlables: $F, \sigma, c, T, \lambda_{S}, b_{S}$

2) Let $\sigma$ vary:

Independent Variables: $F_{o}, a_{0}, m, m^{\prime}, \lambda_{c}, b_{c}, \lambda_{b}, \lambda_{F}, \sigma$ Dependent Variables: $F, c, s, T, \lambda_{s}, b_{s}$

3) Let $F$ vary:

Independent Varlables: $F_{O}, a_{0}, m, m^{\prime}, \lambda_{c}, b_{c}, \lambda_{b}, \lambda_{F}, F$ Dependent Variables: $\sigma, c, s, T, \lambda_{s}, b_{s}$

4) Let $T$ vary:

Independent Variables: $F_{o}, a_{0}, m, m^{\prime}, \lambda_{c}, b_{c}, \lambda_{b}, \lambda_{F}, T$ Dependent Variables: $F, \sigma, c, s, \lambda_{s}, b_{s}$

A more interesting form can be seen if $\sigma$ is chosen as an independent variable. Then (4-15) can be solved for the $\lambda_{s}$ contained in $\mu$ :

$$
\begin{aligned}
\lambda_{S} & =\delta m^{\prime} \lambda_{F} Z(2-z), \\
& =\delta m^{\prime} \lambda_{F}\left(1-(1-z)^{2}\right),
\end{aligned}
$$

where

$$
Z=\left(F_{0} / a_{0}\right)(1-\sigma / \sqrt{1-\alpha})
$$

The resulting curve is displayed in figure $b-2$ :

This curve is characterized by two well defined points. The first is the point where the first unit of storage comes in, with a marginal value $\lambda_{\text {so }}$ which both (5-2) and (5-4) agree has the value

$$
\lambda_{\text {so }}=\delta m \cdot \lambda_{F} \text {. }
$$

This occurs at

$$
\sigma_{0}=\left(1-a_{0} / F_{0}\right) \sqrt{1-\alpha},
$$


which is where 5-5 indicates that $Z=1$, corresponding to a maximum for $\lambda_{s}$ as a function of $\sigma$. Above $\sigma_{o}, \lambda_{s}$ declines, as succeeding increments of storage are used more and more rarely. The value of storage reaches zero when $Z=0$ or 2 ; $Z=2$ is an extraneous root with $\sigma$ less than zero if $a_{0}>F_{0} / 2$, but $Z=0$ yields

$$
\sigma_{\mathrm{m}}=\sqrt{1-\alpha}
$$

the maximum solar fraction obtainable in an optimized systems even if storage is free, since there is a limit due to collector costs. At this solar fraction, the value of storage is zero, as can be seen from (5-4).

Note thate there are no systems with $0<\sigma \sigma_{0}$; efther collectors are not worth buying $\left(\alpha \geq 1\right.$ ) and $\alpha=0$ or they are worth buying $\left(\alpha\langle 1)\right.$ and $\sigma \geq \sigma_{0}$. This effect will usually cover over the discontinulties due to buy-in costs of collectors $\left(b_{c}\right)$, since spreading $b_{c}$ outover collector area sufficlent to make $\sigma=\sigma_{0}$ will usually ensure that total system costs are lower for the solar than for the non-solar system. This should b checked, however, since elther high marginal or buy-in collector costs or a value of $a_{0} / F_{0}$ close to one can produce a small $\sigma_{0}$ and a system which is not cost effective $\left(\mathrm{T}\left(\mathrm{C}^{0}, 0\right)>\mathrm{T}(0,0)\right.$ ) even if $\alpha<1$ and $\sigma_{0}>0$. If storage is to have a value for any given value $f s$ (or $\sigma$ ), $T\left(c^{0}, s\right)$ must be less than $T(0,0)$ for that value of $s$ when $\lambda_{s}$ and $b_{s}$ are taken equal to zero in $\mathrm{Eq} .(4-1)$.

So far, I have shown that the marginal value of storage, $\lambda_{s}$, is determined if either $s$ or $\sigma$ is given. What about the buy-in cost of storage, $b_{s}$ ? If we assume that storage is avallable at a marginal cost just equal to the marginal value (at a given $s$ or $\sigma$ ), then we can use the criterion of overall economic viablity, Eq. $(4-17)$, to find

$$
\begin{aligned}
& b_{s} \leq \lambda_{F} \delta\left(F_{O}-a_{O}(1-\sqrt{1-\mu / \delta})\right) \\
& -\lambda_{F} a_{O} \mu \ln (\sqrt{\delta / \mu}+\sqrt{\delta / \mu-1})-b_{c},
\end{aligned}
$$

where $\mu$ is determined from $\lambda_{s}$, a function of $s$ or $\sigma$. The right side ot Eq. (5-9) may then be regarded as a "breakeven buy-in cost" for storage, a value which the actual buy-in cost must not exceed if economic viability is $L$ be maintained. It 18 convenient that the structure of the equation is sufficlently indeterminate to permit $b_{s}$ to be moved from the "Independent variable" lists as been done in Table 5-1.

Another quantity which is sometimes used, and which is included here for completeness, is the average value of sturage, $V_{S}$. It corresponds to the savings attributable to all storage in the system. I present only the forms where $s$ is the independent variable, although $\sigma$ could be used as well: 


$$
\left.\mathrm{V}_{\mathrm{S}}=\left(\mathrm{T}\left(\mathrm{c}^{\mathrm{O}}(0), 0\right)\right)-\mathrm{T}\left(\mathrm{c}^{\circ}(\mathrm{s}), \mathrm{s}\right)\right) / \mathrm{s}
$$

where $c^{\circ}(s)$ is given by $(4-10)$ and $T$ by $(4-16)$ with $\lambda_{s}=b_{s}=0$. Here the comparison is between two separately optimized systems, with differing collector areas. Thus some of $\mathrm{V}_{\mathrm{S}}$ comes from fuel savings, but there is also a negative component associated with the costs of extra collectors needed to re-optimize after adding the substantial increment of storage, s. Substitution gives:

$$
v_{s}=\lambda_{F} a_{O} \tanh \left(m^{\prime} s / a_{0}\right) / s
$$

Note that $V_{s} \rightarrow \lambda_{\text {so }}$ as $s \rightarrow 0$. The average value of storage is shown as dashed lines in Figures 5-1 and 5-2. Note that $v_{s}$ incorporates both the variable cost of storage and the buy-in cost, $b_{s}$. If $V_{S}$ is too small to incorporate both cost componants, one must say storage has non average value in those circumstances; generally this will only occur for small s to $t$.

The graphs make the problem quite apparent: the value of storage depends (within limjts) on the amount of storage in the system, or, equivalently; on the solar fraction of the system. Unfortunately, there is no clearcut way around the ambiguities in the choice of breakeven costs for storage; some fairly arbitrary choice which will carry a significant amount of the information in these equations and figures must be made. We can, for example, use one of the following marginal value-solar fraction pairs which to some extent typify the curve of $\lambda_{s}$ versus $\sigma$ :

$$
\begin{aligned}
& B_{0}=\lambda_{s o} ; \sigma_{0} \\
& B_{1}=\lambda_{s o} / 2 ; \sigma_{1}=\sigma\left(\lambda_{s o} / 2\right) \\
& \sigma_{2}=\left(\sigma_{0}+\sigma_{m}\right) / 2 ; B_{2}=\lambda_{s}\left(\sigma_{2}\right) \\
& B_{3}=\left(1 /\left(\sigma_{\mathrm{m}}-\sigma_{0}\right)\right) \int_{\sigma_{0}}^{\sigma_{m}} \lambda_{s}(\sigma) d \sigma ; \sigma_{3}=\sigma\left(B_{3}\right)
\end{aligned}
$$

These are presented in order of increasing complexity. While simplicity is desireable, indicating that (5-12) might be preferable, a desire to refer to systems having substantial amounts of storage, for which buy in costs are spread over larger amounts of storage, would lead to the choice of (5-13). In any event, breakeven buy-in costs can be found from Eq. (5-9) once a choice has been made. Equation (5-15) is almost certainly too complicated to be worth working with. As we will see, the issues to be raised in the next section will render these choices less important. 


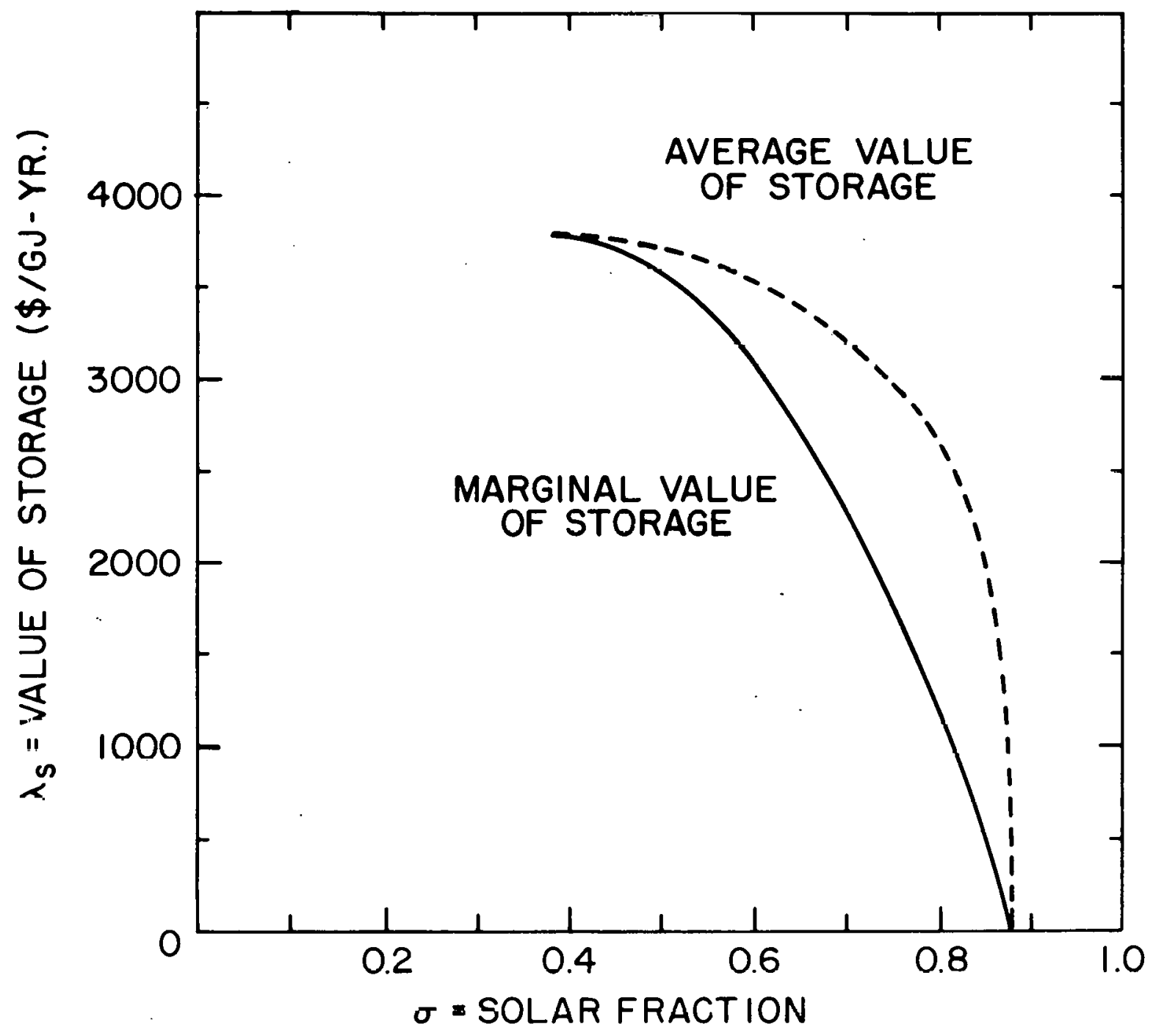

Figure 5-2

Value of Storage vs. Solar Fraction 


\section{VALUE OF STORAGE-DEPENDENCE ON THE COST OF COLLECTORS}

In the preceeding section $\lambda_{c}$, the cost of collectors, was assumed known. In reality, the future cost of collectors is not known, will hopefully be lower than it is today, and will almost certainly depend on the $R$ and $D$ effort expended on lowering it, albeit in an unpredictable way. The calculated value of storage must then depend parametrically on the cost of collectors. In fact, it is perhaps more reasonable to regard both $\lambda_{c}$ and $\lambda_{s}$ as breakeven costs and ask what mix of these two breakeven costs will be most beneficial to society in the future. As I have pointed out, it would be advantageous if such a calculation could include estimates of how much savings can be bought, in both $\lambda_{c}$ and $\lambda_{S}$, by a given $R$ and $D$ expenditure, but such estimates are so uncertain that it would be delusory to use them quantitatively in policy decisions. Accordingly, I will consider only benefits apparent within the confines of the analysis of individual systems.

One way to see the relation of the values of storage and solar is to plot what might be called isusolars -- curves in the $\lambda_{c}-\lambda_{s}$ plane that represent systems of constant solar fraction. These may be easily calculated from Eqs. (5-3) and (5-5), and are plotted in Figure 6-1 for our example system. The trade-offs are obvious. If $\lambda_{c}$ increases, the $\lambda_{s}$ necessary for a constant solar fraction decreases and vice versa. But is there an optimal solution?

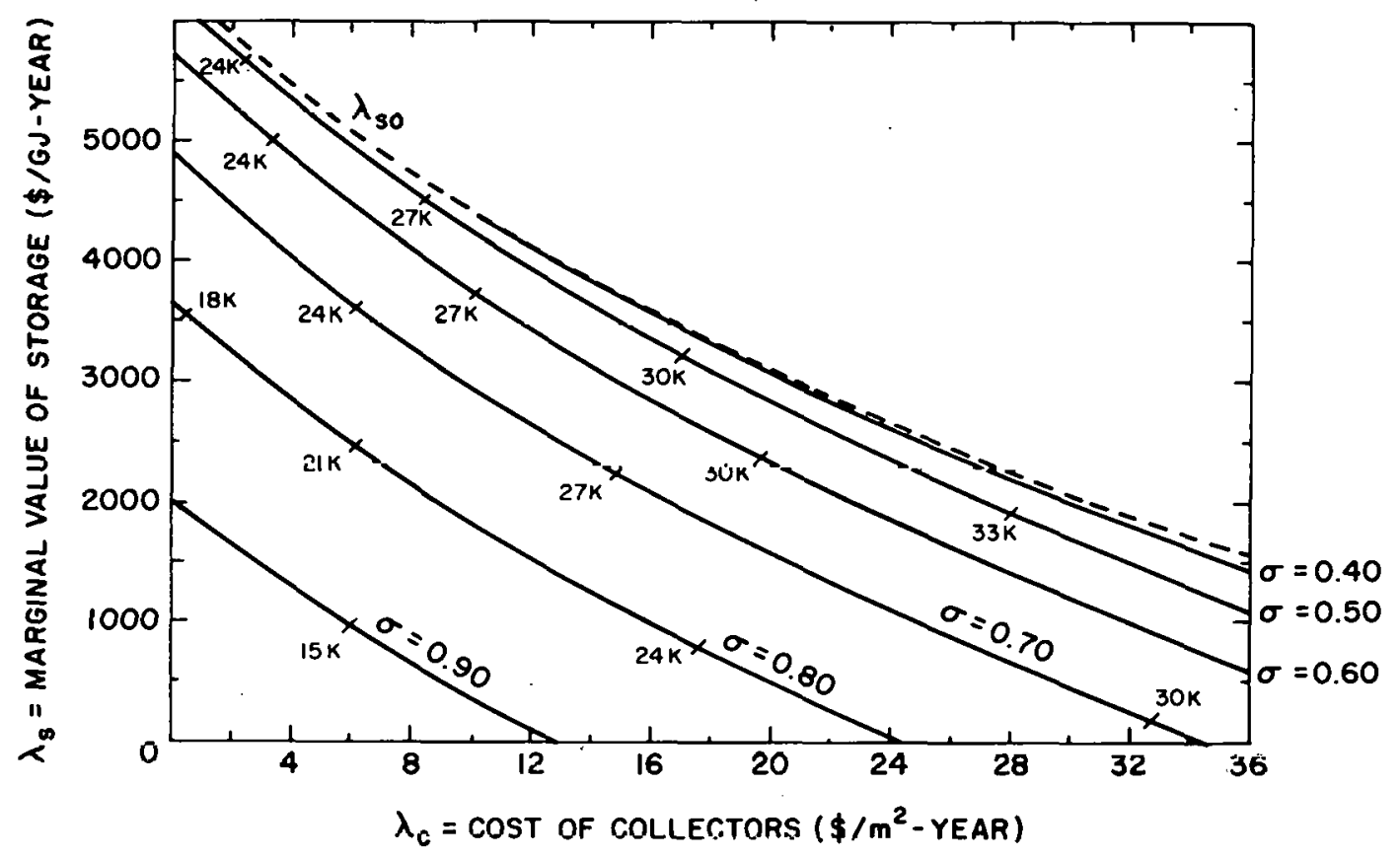

Figure 6-1

Value of Storage vs. Cost of Collectors in Optimized Systems of Constaut Solar Fraction Total Annual System Cost Shown as $21 \mathrm{~K}=\$ 21,000$ 
This amounts to asking if there is a point of minimum total cost for each iso-solar. To find this, for each $\lambda_{c}$ and $\sigma$, get $\lambda_{s}$ from Eq. (5-3), $c^{\circ}$ and $s^{\circ}$ from Eqs. (4-12) and (4-13), F from Eq. (4-14) and plug them all into Eq: (4-16) for T. Note that only the costs associated with collectors and storage vary, since we are on isosolars and fuel consumption is constant. The results are printed onto Figure 6-1 for a few values of $\sigma$, although the pattern holds for all of them: total costs are minimized if $\lambda_{c}$ approaches zero, permitting $\lambda_{s}$ to be quite large. (Attainable values of $\lambda_{c}$ for this example are probably in the range of $\left.10-15 \$ / \mathrm{m}^{2}-\mathrm{yr}_{.}\right)$This particular approach indicates that it is sufficlent to bring the costs of storage devices down to the range where optimized systems are possible, but that beyond this point, more savings will accrue from reductions in the cost of collectors than from reductions in the cost of storage.

This analysis is somewhat unsatisfying, however, since there is nothing sacred about a constant solar fraction, and the possibility that this assumption has produced the observed results is troubling. Accordingly, another approach, isocost curves in the $\lambda_{c}-\lambda_{s}$ plane, is shown in Figure 6-2. This calculation is based on the notion that what people have is a certain amount of money they can spend on a solar energy system, so the question becomes what will their options be as $\lambda_{c}$ and $\lambda_{s}$ are varied? Calculating these curves is less direct than the previous work and relies on iterative techniques. For each $\lambda_{c}$ and $T_{o}$ (the total cost sought) a $\lambda_{s}$ is chosen and $c^{0}, s^{0}$ and $F$ are again found from Eqs. (4-12), (4-13), and (4-14) and used in (4-16) to give $T$. $\lambda_{s}$ is then varied iteratively unt $11 \mathrm{~T}=\mathrm{T}_{0}$, and then $\sigma$ is calculated at that point also.

For each isocost curve in Figure 6-2, the point of maximum solar fraction and hence maximum fuel displacement is shown as a bar intersecting the curve.

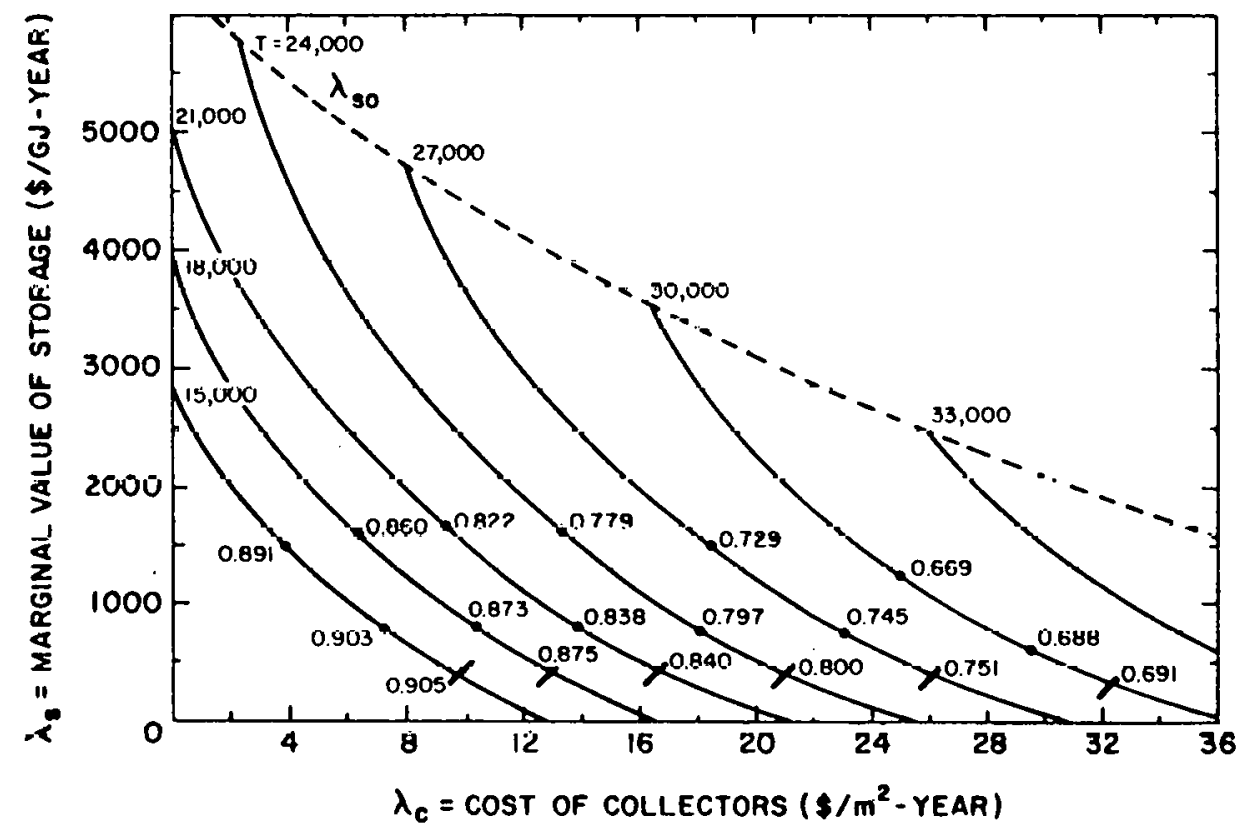

F1gure 6-2

Value of Storage vs. Collector Cost for Systems of Constant Total Cost 
If we assert that for a given total cost, maximal societal benefit is obtained for maximal fuel displacement, then the loci of these points trace out the set of $\lambda_{c}, \lambda_{s}$ pairs which is most desirable.

This is interesting because it implies that the optimal $\lambda_{s}$ varies only very slowly with $\lambda_{C}$, so storage $R$ and $D$ has a stable target independent of collector costs. Put another way, attainable total costs and solar fractions of systems which are optimal in the sense of maximal fuel displacement depend strongly on collector costs and not so strongly on storage costs.

Also, the actual breakeven costs shown in Figure 6-2 are not critical. The maximum in solar fraction along an isocost curve is extremely broad; the dots and extra numbers on each isocost in Figure 6-2 indicate the solar fraction at points where the value of storage is two and four times what it is at the maximum, and the variation is only 2 or $3 \%$ for large changes in collector costs. Thus it is not necessary to achieve the (fairly stringent) breakeven costs of storage corresponding to absolutely maximal fuel displacement indicated by the bars in Figure 6-2; failing by a factor of four will result in a solar fraction which is about $3 \%$ lower at the same system cost if collector costs can be reduced by $20 \%$, and reducing collector costs $20 \%$ is almost certainly easier than reducing storage costs by a factor of four.

Thus, the two analyses indicate that $\lambda_{c}$ has a far more direct effect on solar fraction and on total costs than has $\lambda_{s}$. As long as storage targets are chosen and achieved which make optimized systems possible, the cost of collectors must bear the primary burden for subsequent total cost reductions and increases in solar fraction.

Does this result depend on the particular parameter set chosen? Consider the observations on Figure 6-1, where the total cost was found to be smallest when collector costs were smallest and storage costs remained finite. The straightforward way to generalize this result would be to find a general solution for the $\left(\lambda_{c}, \lambda_{s}\right)$ which gives the minimum of $T\left(\lambda_{c}, \lambda_{s}\right)$ under the constraint $\sigma\left(\lambda_{c}, \lambda_{s}\right)=$ a constant. The result would presumably be $\lambda_{c}>0, \lambda_{s}$ finite. This can be done in principle using Lagrange multipliers, but in practice the equations are too complex to be solved in general, and we must proceed numerira11y.

To simplify the investigation, we reduce all quantities of interest to dimensionless variables similar to the dimensionless collector cost, $\alpha$, and the dimensionless storage (breakeven) cost $\mu$, introduced in Eqs. (4-6) and (4-9). The reduced collector area, $\pi$, is then found from Eq. (4-13) to be (for an optimized system)

$$
\pi=\sigma_{0} /\left(F_{0} / m\right)=R\left(1-\left(a_{0} / F_{0}\right)(1-\sqrt{1-11 / \delta})\right),
$$

and the reduced storage capacity, $Y$, is found from Eq. (4-12) to be 


$$
Y=s^{0} /\left(F_{0} / m^{\prime}\right)=\left(a_{0} / F_{0}\right) \ln (\sqrt{\delta / \mu}+\sqrt{\delta / \mu-1})
$$

Note that we are measuring collector area (storage capacity) in units of the amount of collector (storage) needed to displace $F_{0}$ units of fue 1 if the collectors (storage) all worked at the same performance level as the first unit.

The reduced collector cost $\alpha$ is still given by Eq. (4-6), while for systems of given solar fraction we obtain $\mu$, the reduced storage cost corresponding to this solar fraction by inverting Eq. (4-15) to find

$$
\mu=\delta\left(1-\left(1-\left(F_{0} / a_{0}\right)(1-\sigma / \sqrt{1-\alpha})\right)^{2}\right)
$$

We then use Eq. (4-16) to define a reduced total cost

$$
t=T / F_{O} \lambda_{F}=1-\sigma+\alpha \pi+\mu \gamma+\text { constant terms. }
$$

Inspection makes it clear that in these units there is only one technical parameter, $a_{0} / F_{o}$. It is then easy to calculate $\pi, \gamma, \mu$, and $t$ as functions of $\alpha$ along curves of constant $\sigma$ for various values of $\left(a_{0} / F_{0}\right)$ covering the range of physical interest. These quantities are plotted in Figures 6-3 through 6-6. Note that many curves terminate at a value of $\alpha$ where the amount of storage becomes zero, and that the value of storage becomes zero at the $\alpha$ for which infinite storage is needed. Examination of Figure 6-6, showing reduced total cost, Indicates that although there is often a maximum cost just below the value of $\alpha$ for which $\gamma$ becomes infinite, with a slight decrease in $t$ for larger $\alpha^{\prime} s$, the total cost never approaches the low value it had for smaller $\alpha^{\prime} s$. (This behavior has been examined over a broader range of parameters than can be shown on the graphs and still holds.) The fact that this dependence of $t$ on $\alpha$ holds for the complete relevant range of $\alpha$ for all systems describable by these equations verifies the conclusion that a reduction in collector costs has a greater Impact on the economic competitiveness of these systems than does lowering storage costs.

A "reduced breakeven buy-in cost" of storage may be defined as $b_{s} / \lambda_{F} F_{0}$ and evaluated using Eq. (5-9). The result is the same" for systems of constant solar fraction, the reduced breakeven buy-in cost is maximal for the smallest reduced collector cost, and becomes monotonically smaller as $\alpha$ is increased, so even as total system costs are increasing, less and less money is available to cover the fixed costs of storage. Stated succintly, decreasing collector costs at constant solar fraction simultaneously increases the allowed marginal cost of storage and the allowed buy-in cost of storage while lowering total system costs. 
Figure 6-3

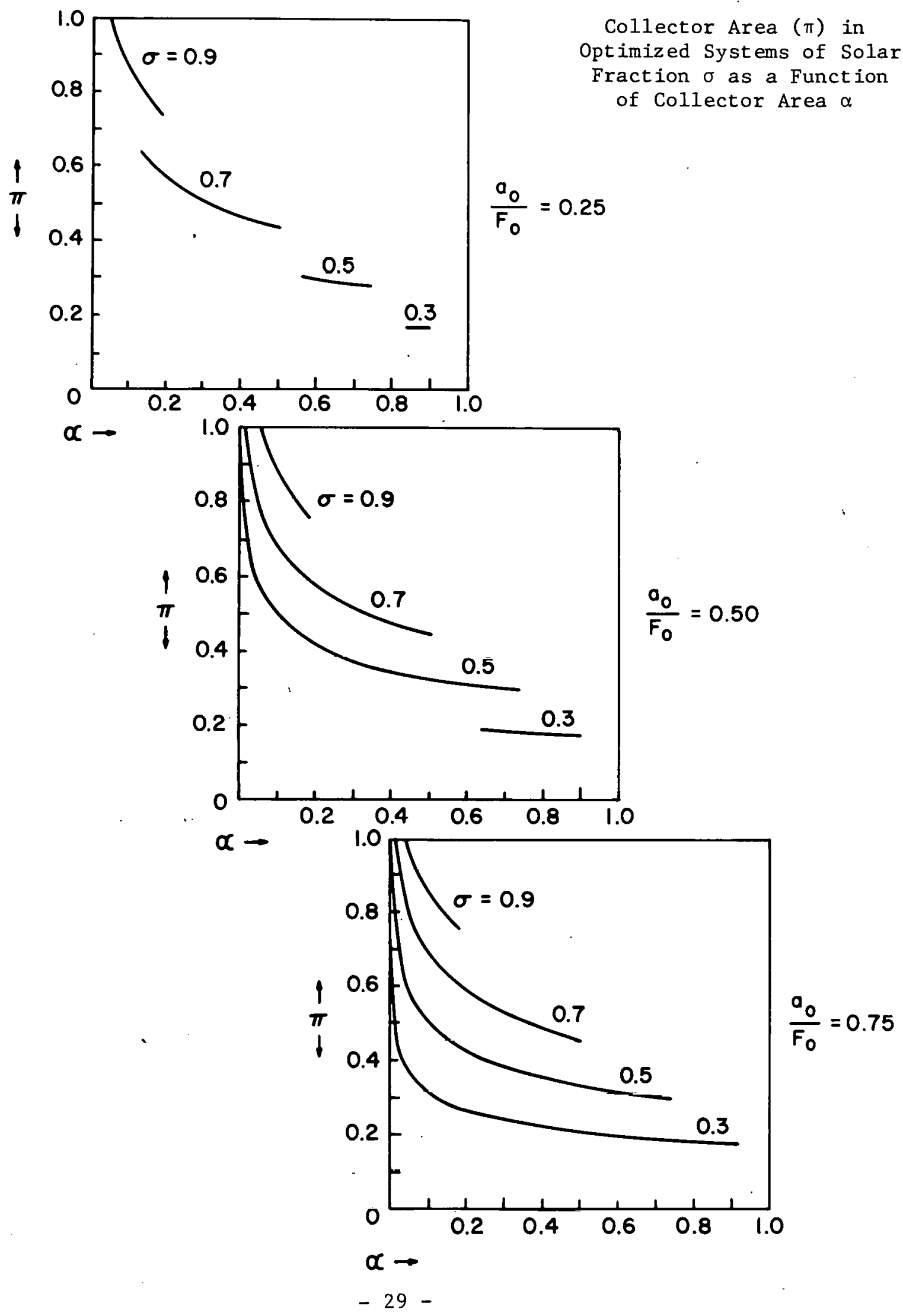


Figure 6-4

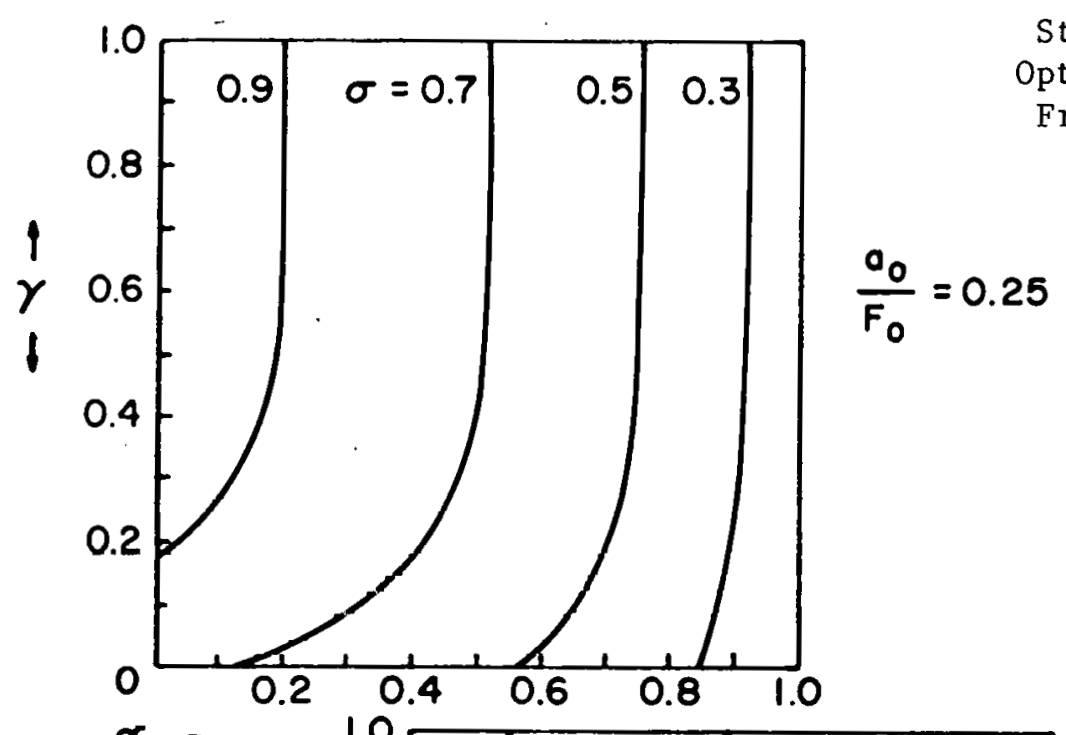

Storage Capacity $(\gamma)$ in Optimized Systems of Solar

Fraction $\sigma$ as a Function of Collector Cost $\alpha$

$\frac{a_{0}}{F_{0}}=0.25$ $\propto-$

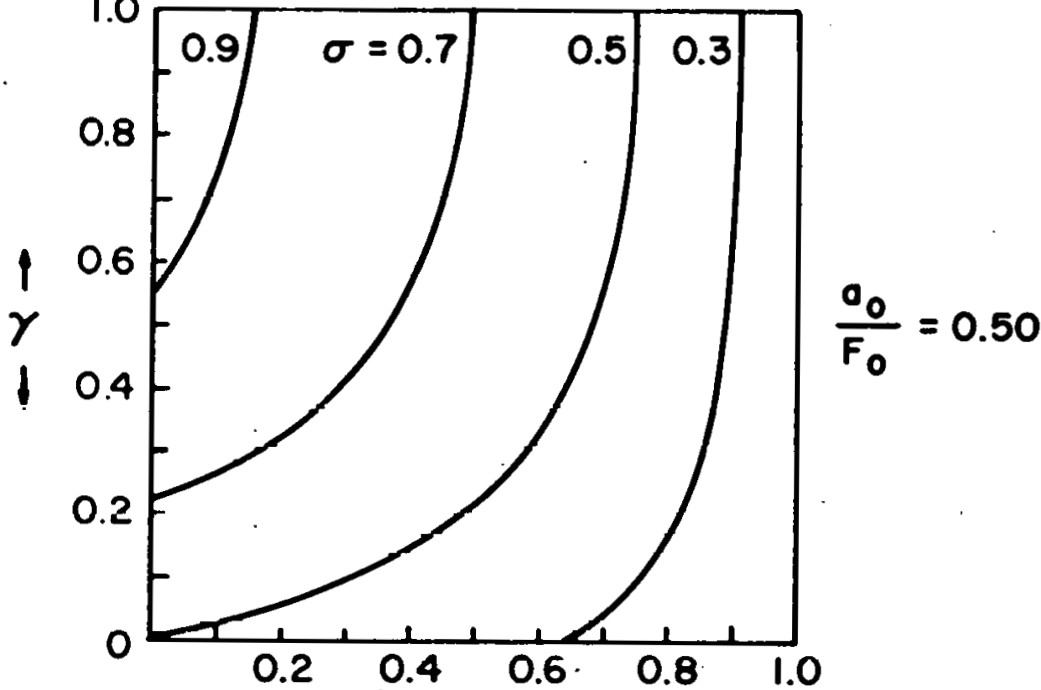
$\propto \rightarrow$

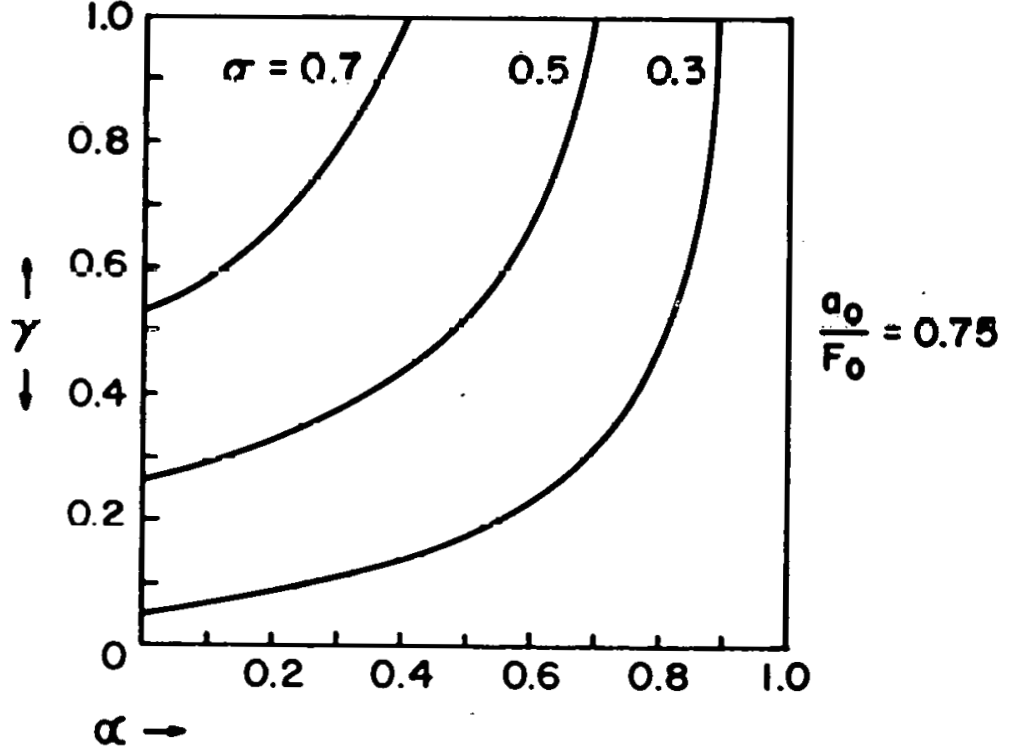


Figure 6-5

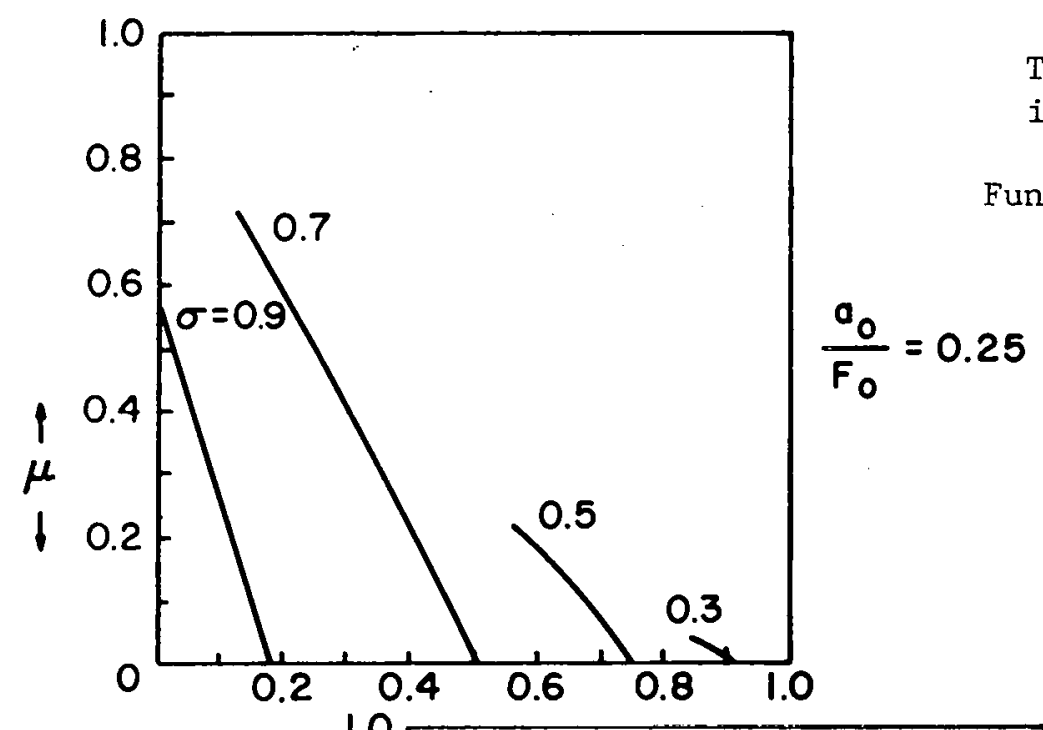

$\propto \rightarrow$

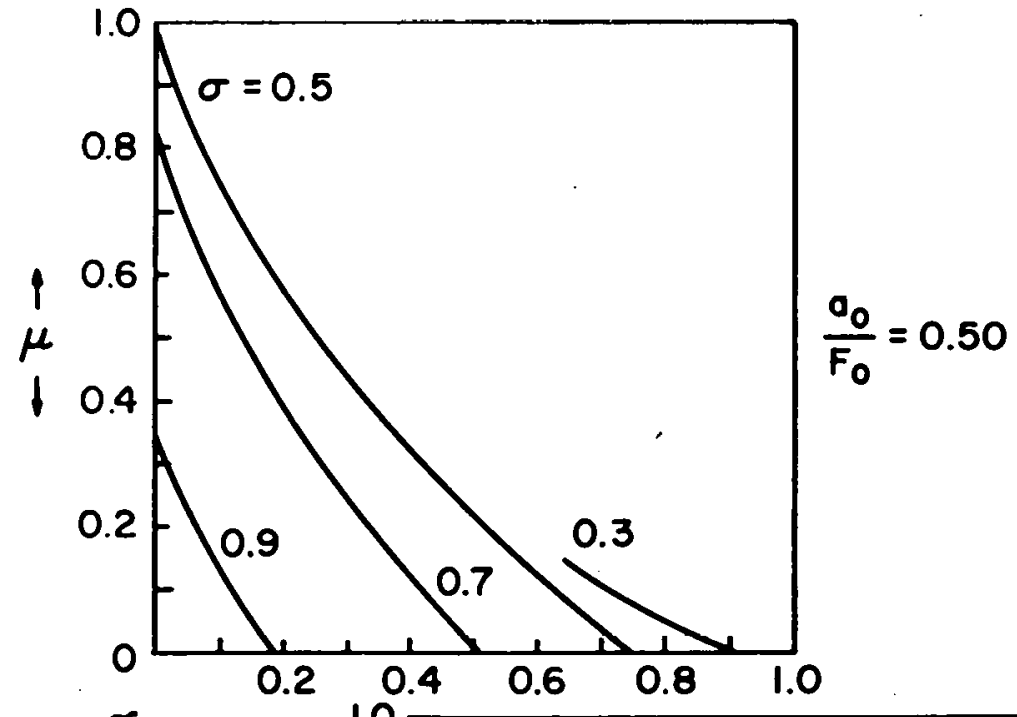

$\alpha \rightarrow$

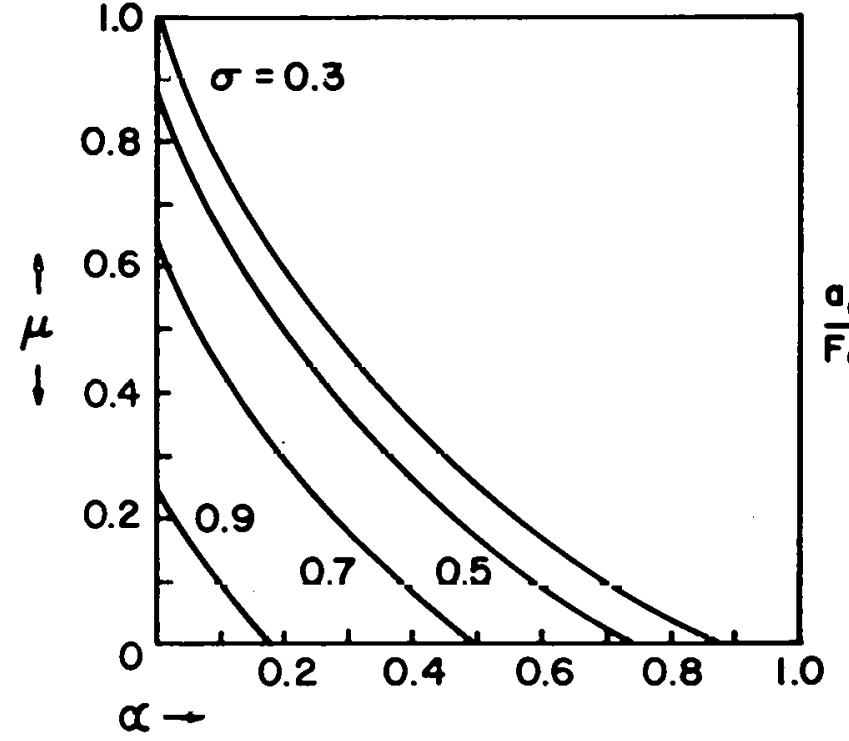

The Value of Storage ( $\mu)$ in Optimized Systems of

Solar Fraction $\sigma$ as a

Function of Collector Cost $\alpha$ $\frac{a_{0}}{F_{0}}=0.75$ 
Figure 6-6

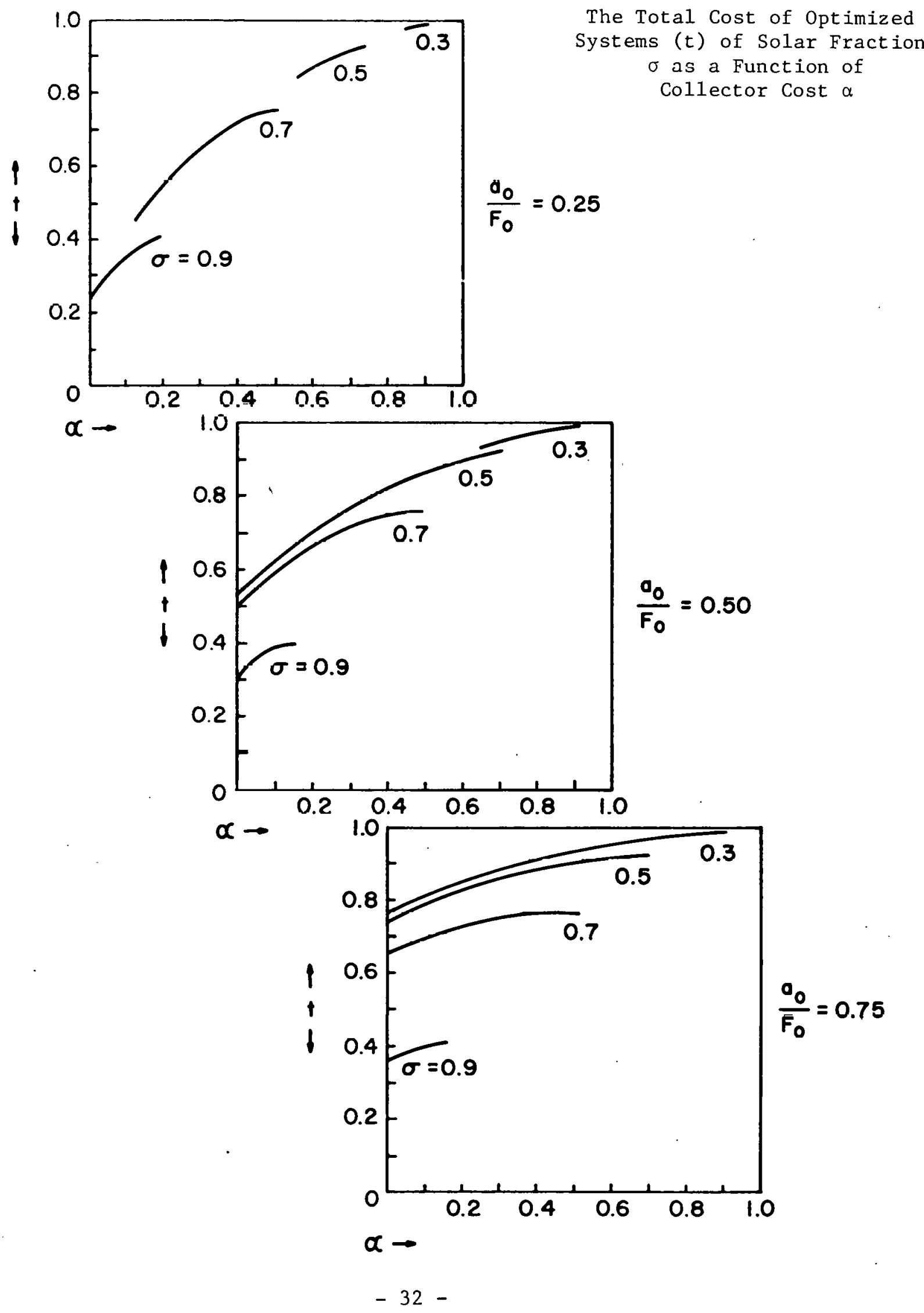




\section{REFERENCES}

1. Leigh, R.W., Storage in Residential Solar Total Energy Systems, BNL 51230, Brookhaven National Laboratory, Upton NY 11973, Dec. 1980.

2. Grant, E.L., Ireson, W.G., and Leavenworth, R.S., Principles of Engineering Economy, $6^{\text {th }}$ ed., (John Wlley and Sons, New York NY, 1976),

3. Office of Technology Assessment, Congress of the United States, Application of Solar Technology to Todays Energy Needs, Vo1. 2, Chapter 1) (U.S. GPO, Washington DC, Sept. 1978)

4. Chemical Engineering Directorate, The Aerospace Corporation, Uniform Assessment Methodology for Energy Storage Applications, Report $80-520$, (Germantown MD, Dec. 1980).

5. Reference 1, Appendix A.

6. Dr. D. Caskey, Sandia Laboratories, private communtcation.

7. I was reminded of the importance of buy-in costs by a presentation given by Dr. Ari Rabl of SERI at the Solar Applications Analysis for Energy Storage Program Review Meeting on July 15, 1981 at SERI.

* U.S. GOVERNMENT PRINTING OFFICE: 714-037\#27 